\title{
Congenital generalized lipodystrophy
}

\author{
Paulo P. Figueiredo Filho, ${ }^{1}$ Alexandre Costa Val, ${ }^{2}$ Rosângela Diamante, ${ }^{1}$ \\ Cristiane F. Cunha, ${ }^{3}$ Rocksane C. Norton, ${ }^{3}$ Joel A. Lamounier, ${ }^{3}$ Ênnio Leão ${ }^{4}$
}

\begin{abstract}
Objective: To present the major clinical and biochemical characteristics of congenital generalized lipodystrophy.

Description: Eight infants with congenital generalized lipodystrophy were identified at the Endocrine and Nutritional Pediatric Disease Outpatient Clinics at Hospital de Clínicas, Universidade Federal de Minas Gerais (UFMG). Clinical manifestations common to all patients included muscle hypertrophy, generalized lipoatrophy, and acromegalic physical appearance. Acanthosis nigricans was identified in five patients, hepatosplenomegaly in six, hypertriglyceridemia and low levels of HDL cholesterol in seven, cardiac hypertrophy in one and diabetes mellitus in two patients. All patients are under dietetic and clinical control.

Comments: The phenotypic characteristics of congenital generalized lipodystrophy are well identified, which, in most cases, favors the clinical diagnosis. The congenital generalized lipodystrophy is a very unusual syndrome that illustrates the importance of the adipose tissue for the majority of metabolic processes. A better understanding of this syndrome may open new horizons in the research of more prevalent diseases such as diabetes mellitus and obesity.
\end{abstract}

J Pediatr (Rio J). 2004;80(4):333-6: Lipodystrophy; diabetes mellitus; hypertriglyceridemia.

\section{Introduction}

Generalized lipodystrophy is a disorder of the lipid and carbohydrate metabolism clinically characterized by varying levels of fat loss in adipose tissues. Adipose cells are scarce and have a low volume due to the fact that they are unable to store lipids. Currently, lipodystrophy is classified as partial or total (generalized) and congenital or acquired. ${ }^{1-3}$

Congenital generalized lipodystrophy, first described in Brazil in 1954 by Berardinelli and reviewed by Seip in 1959, became known as Berardinelli-Seip syndrome. ${ }^{4}$ It

1. Assistant professor, Department of Pediatrics, School of Medicine, Universidade Federal de Minas Gerais (UFMG), Belo Horizonte, MG, Brazil.

2. Medical student, School of Medicine, Universidade Federal de Minas Gerais (UFMG), Belo Horizonte, MG, Brazil.

3. Associate professor, Department of Pediatrics, School of Medicine, Universidade Federal de Minas Gerais (UFMG), Belo Horizonte, MG, Brazil.

4. Emeritus professor, Department of Pediatrics, School of Medicine, Universidade Federal de Minas Gerais (UFMG), Belo Horizonte, MG, Brazil.

Manuscript received Jul 09 2003, accepted for publication Jan 072004. is a rare disorder with a prevalence of less than one case per 12 million individuals ${ }^{5}$ and with an autosomal recessive inheritance pattern that affects all ethnic groups. According to Garg, ${ }^{5} 120$ cases have been described on a worldwide basis. This disease is clinically characterized by loss of adipose tissue (especially in subcutaneous fat), muscular hypertrophy, long extremities (feet, hands, jaw), acromegalic appearance, accelerated growth, hypertrophic cardiomyopathy and hepatosplenomegaly. Additional exams show advanced bone age, evidence of liver dysfunction (increase in aminotransferases), dyslipidemia (increase in triglycerides, decrease in $\mathrm{HDL}$, with possible elevation of total cholesterol and LDL levels), glucose intolerance or diabetes mellitus, hyperinsulinemia and cardiomegaly. 6 Familial partial types (Dunningan, Kobberling and Mandibuloacral) also have been described.

The acquired type may be related to autoimmune disorders caused by infections. Clinical symptoms resemble those of the congenital type, especially when there is early involvement. ${ }^{7}$ 


\section{Case reports}

Eight children and adolescents were diagnosed with congenital generalized lipodystrophy (Berardinelli-Seip syndrome) at the outpatient clinic of Nutritional Disorders and Endocrinology of the Division of Pediatrics of Hospital das Clínicas (Universidade Federal de Minas Gerais - UFMG). The ages of the patients, three males and five females (two of whom were sisters), ranged from three months to 19 years (Table 1). Family history of the disease symptoms was present, although the syndrome was not diagnosed in most of the cases.

Table 1 - Patients' characteristics

\begin{tabular}{ccccc}
\hline Case & $\begin{array}{c}\text { Sex } \\
\text { (years) }\end{array}$ & $\begin{array}{c}\text { Current age } \\
\text { (months) }\end{array}$ & $\begin{array}{c}\text { Age at } \\
\text { diagnosis }\end{array}$ & $\begin{array}{c}\text { Siblings } \\
\text { affected }\end{array}$ \\
\hline I & F & 19 & 2 & Yes \\
II & F & 16 & 3 & Yes \\
III & M & 16 & 12 & No \\
IV & F & 15 & 2 & No \\
V & M & 3 & 5 & No \\
VI & M & 2 & 6 & No \\
VII & F & 2 & 2 & No \\
VIII & F & $1 / 4$ & 3 & No \\
\hline
\end{tabular}

The most characteristic phenotype in all patients included generalized lipoatrophy, muscular hypertrophy, acromegalic appearance, and dry and thick hair. Five children had acanthosis nigricans and six presented with hepatosplenomegaly. The following disorders were observed with less frequency: xanthomas, cardiac hypertrophy, hypertension, diabetes mellitus, hyperinsulinemia, ovarian cysts, and enlargement of parotid glands and clitoris. There was one case of acute pancreatitis secondary to hypertriglyceridemia in one of the patients at the age of 17 years. The following biochemical findings were observed: increase in aminotransferase concentration in four children, hypertriglyceridemia associated with reduction in HDL concentration in seven patients, and microalbuminuria in one child. Radiological findings included areas of long bone sclerosis and cardiomegaly (Tables 2 and 3; Figure 1). Growth hormone levels were normal.

Table 2 - Main data at physical examination

\begin{tabular}{|c|c|c|c|c|c|c|c|c|c|}
\hline Data\Patient & $\mathbf{I}$ & II & III & IV & $\mathbf{v}$ & VI & VII & VIII & Total \\
\hline Generalized lipoatrophy & + & + & + & + & + & + & + & + & 8 \\
\hline Muscular hypertrophy & + & + & + & + & + & + & + & + & 8 \\
\hline Acromegalic appearance & + & + & + & + & + & + & + & + & 8 \\
\hline Dry and thick hair & + & + & + & + & + & + & + & + & 8 \\
\hline Hepatosplenomegaly & + & - & - & + & + & + & + & + & 6 \\
\hline Acantosis nigricans & + & + & - & + & + & - & + & - & 5 \\
\hline Xanthomas & + & - & - & + & - & - & - & - & 2 \\
\hline Hypertension & + & + & - & - & - & - & - & - & 2 \\
\hline Cardiac hypertrophy & - & - & - & - & - & + & - & - & 1 \\
\hline
\end{tabular}

+ Present; - Absent.

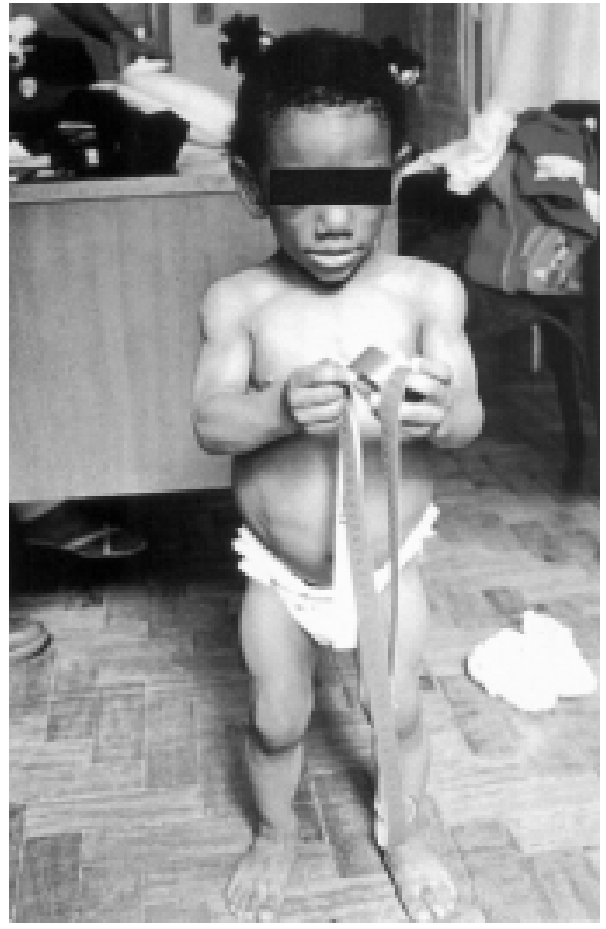

Figure 1 - Recent picture of the patient of case VII shows typical phenotype of congenital generalized lipodystrophy with muscle lipoatrophy and hypertrophy

Dietary restriction was the most important therapeutic measure. Two patients are taking enalapril and metformin to control hypertension and insulin resistance, and one patient is using glibenclamide.

\section{Discussion}

Congenital generalized lipodystrophy is a rare autosomal recessive disease, with a quite characteristic phenotype. Lack of subcutaneous adipose tissue and muscular hypertrophy are prominent from the first months of life, and low weight gain is frequently observed. The acquired type is similar to the congenital one, but may vary in terms of anabolism depending on the age at onset. ${ }^{4-6}$

Enlarged extremities (hands, feet, ears and nose) were observed in all patients, giving them an acromegalic appearance. However, growth hormone levels were appropriate for age. Acanthosis nigricans, detected in five patients, can be attributed to peripheral insulin resistance. Other common findings include curly and frizzy hair, dry and thick skin, hypertrichosis, hyperhidrosis, large prominent veins and xanthomas. ${ }^{3,6}$

The morphological and functional study of the skeletal musculature of patients with this disease suggests that increased muscle mass results from hyperplasia instead of hypertrophy, showing no association with increased strength. 8 
Table 3 - $\quad$ Lipid profiles, hepatic function and glucose tests of patients

\begin{tabular}{|c|c|c|c|c|c|c|c|c|}
\hline Findings $\backslash$ Patients & $\mathbf{I}$ & II & III & IV & $\mathbf{v}$ & VI & VII & VIII \\
\hline Total cholesterol (RV* $<200 \mathrm{mg} \%$ ) & 172 & 124 & 124 & 173 & 108 & 163 & 133 & 136 \\
\hline LDL $(\mathrm{RV}<130 \mathrm{mg} \%)$ & - & 67 & 69 & 90 & 57 & 85 & 27 & 57 \\
\hline $\begin{array}{l}\mathrm{HDL}(\text { normal }=<10 \text { years } \geq 40 \mathrm{mg} \% \\
\geq 10 \text { years }>35 \mathrm{mg} \%)\end{array}$ & 17 & 29 & 28 & 35 & 34 & 24 & 35 & 25 \\
\hline $\begin{array}{l}\text { Triglycerides }(\mathrm{RV}=<10 \text { years } \geq 100 \mathrm{mg} \% \\
>10 \text { years } \geq 130 \mathrm{mg} \%)\end{array}$ & 1,253 & 139 & 135 & 240 & 87 & 270 & 353 & 268 \\
\hline GOT $(\mathrm{RV}=10-70 \mathrm{U} / \mathrm{I})$ & 32 & 25 & 22 & 92 & 47 & 35 & 28 & 45 \\
\hline GPT $(R V=10-60 \mathrm{U} / \mathrm{I})$ & 61 & 41 & 51 & 165 & 98 & 65 & 76 & 59 \\
\hline $\begin{array}{l}\text { Glucose level after overnight fast } \\
(\mathrm{RV}=70-110 \mathrm{mg} \%)\end{array}$ & $\begin{array}{l}414 \\
332\end{array}$ & $\begin{array}{c}82 \\
107\end{array}$ & $\begin{array}{l}83 \\
85\end{array}$ & $\begin{array}{l}266 \\
367\end{array}$ & $\begin{array}{l}88 \\
97\end{array}$ & $\begin{array}{l}85 \\
95\end{array}$ & $\begin{array}{l}74 \\
78\end{array}$ & $\begin{array}{c}84 \\
-\end{array}$ \\
\hline
\end{tabular}

${ }^{*}$ Reference value; ${ }^{\dagger}$ two measurements.

Hepatosplenomegaly, often accompanied by abnormal liver function tests, may cause triglyceride and glycogen levels to increase in hepatocytes, being associated with cirrhosis. 3,4

Dyslipidemia, observed in seven patients, was characterized by an increase in triglyceride levels and a decrease in HDL. A slight increase in total cholesterol levels also was observed. The major deficiency in lipid metabolism apparently lies in the inability of adipocytes to store fat, probably due to the abnormal functioning of glucose transporters (GLUT 1-7) found in adipose, musculoskeletal, and cardiac cells. Consequently, intracellular levels of glycerol are low, hampering the storage of free fatty acids in the form of triglycerides. The metabolic use of lipids and hepatic lipogenesis via carbohydrates are active, although glucose is preferably stored in the form of glycogen as observed in liver and muscle biopsies. Hypertriglyceridemia may result in small fat deposits known as xanthomas, which occur in the palmar, joint, perioral and foot regions. Moreover, high levels of triglycerides may cause acute pancreatitis, observed in one of the reported cases. $3,6,9$

Carbohydrate metabolism is characterized by primary peripheral insulin resistance associated with hyperinsulinemia which, after puberty, results in secondary diabetes mellitus. This finding is related to insulin postreceptor defects in adipocytes, hepatocytes and muscle cells, also participating in the etiology of dyslipidemia. The course of diabetes mellitus, especially in female patients, may be dramatic when combined with early complications (retinopathy, nephropathy, cardiovascular events). These patients are resistant to insulin or oral hypoglycemic drugs. Among reported cases, two female patients were diagnosed with diabetes and one with hyperinsulinemia. 3,9

Hypermetabolism without hyperthyroidism, which is characterized by uncontrolled appetite, excessive food intake and hyperhidrosis, may also be present. This finding is possibly due to an increase in active peroxisomes and mitochondrial defects of the liver and muscle cells, working as a compensatory mechanism, since it helps the body to use up all the excess energy that is not stored as fat. ${ }^{3}$ In the present study, thyroid hormones remained unchanged, but intense appetite and excessive sweating have been reported.

The anabolic process is easily perceived through a fast increase in height, muscular hypertrophy, skeletal sclerosis and enlarged organs. Probably, this process is intensified by hyperinsulinemia associated with hyperglycemia and, just as hypermetabolism, it also has a protective effect, explaining the more severe metabolic disorders that occur after puberty. ${ }^{3,5}$ These findings were observed in all patients, who revealed a faster growth speed, and in some cases, enlarged organs (especially hepatosplenomegaly). Clitoral hypertrophy was found in one case, and enlarged parotid glands were observed in another case. The x-ray of the long bones revealed sclerotic areas in two patients.

Hypertrophic cardiomyopathy may indicate a poor prognosis. Ventricular dysfunction can also be present and deteriorates progressively with age. Increased anabolism, together with excess energy, is the cause of this disorder. Arterial blood pressure may be slightly elevated and is not related to cardiac hypertrophy. ${ }^{3,10-12}$ One of our patients presented with hypertrophic cardiomyopathy and another two had hypertension. None of them suffered from heart failure.

Pubarche in affected girls occurs early on in spite of delayed menarche. Menstrual cycles are irregular and infrequent and ovarian cysts are common. Consequently, fertility is reduced, despite some literature reports showing patients with uneventful pregnancies. ${ }^{3}$

Different forms of nephropathy may be associated with lipodystrophy, resulting from the anabolic process, diabetes mellitus, or hyperlipidemia. ${ }^{3,5}$ One of our patients had persistent microalbuminuria, although other kidney function tests yielded normal results. 
Patients are followed up by a multidisciplinary team (pediatricians, nutrologists, endocrinologists and nutritionists). All of the patients are asked to restrict their total energy intake, as well as their intake of saturated fats and simple carbohydrates, replacing them with complex carbohydrates, soluble fibers, medium chain triglycerides and unsaturated fatty acids. The proper control of triglyceridemia may delay the development of diabetes mellitus. Quite often, the management of this syndrome involves the combination of a wide series of drugs, including insulin, oral hypoglycemics (metformin and thiazolidinediones) and lipid-lowering drugs (fibrates and statins). However, their effects are quite limited as could be observed in some of the patients (cases I, II and IV). Recent studies have proposed replacement therapy with leptin, a protein produced by the adipose tissue that plays an important role in energy homeostasis, which has yielded promising results in controlling lipid and carbohydrate metabolic disorders that are characteristic of this syndrome. 13

The genetic heterogeneity of generalized lipodystrophy, as well as the existence of different stages of the disease, explain the slight differences among the main clinical findings of the patients reported here. Several studies suggest well-defined mutations of the $9 q 34$ and $11 q 13$ genes, thus contributing to the elucidation of mechanisms involved in adipose tissue disorders that result in peripheral insulin resistance, diabetes mellitus and dyslipidemia. One day, such studies may have practical applications for the management of this rare syndrome and more prevalent lipid and carbohydrate disorders, such as obesity and noninsulindependent diabetes mellitus. $3,6,14,15$

\section{References}

1. Ziegler LH. Lipodystrophies: report of seven cases. Brain. 1928; 51:147-67.

2. Silver K, Walston J, Plotnick L, Taylor SI, Kahn CR, Shuldiner AR. Molecular scanning of b-3-adrenergic receptor gene in total congenital lipoatrophic diabetes mellitus. J Clin Endocrinol Metab 1997;82:3395-8.
3. Seip M, Trygstad O. Generalized lipodystrophy, congenital and acquired (lipoatrophy). Acta Paediatr Suppl. 1996;413:2-28.

4. Berardinelli W. An undiagnosed endocrinometabolic syndrome: report of two cases. J Clin Endocrinol Metab. 1954;14:193-204.

5. Garg A. Lipodystrophies. Am J Med. 2000;108:143-52.

6. Garg A. A gene for congenital generalized lipodystrophy maps to human chromosome 9q34. J Clin Endocrinol Metab. 1999;84:3390-4.

7. Behrens GMN, Boerner AR, Weber K, Hoff JVD, Ockenga J, Brabant $\mathrm{G}$, et al. Impaired glucose phosphorylation and transport in skeletal muscle cause insulin resistance in HIV-1-infected patients with lipodystrophy. J Clin Invest. 2002;110:1319-27.

8. Garg A, Stray-Gundersen J, Parsons D, Bertocci LA. Skeletal muscle morphology and exercise response in congenital generalized lipodystrophy. Diabetes Care. 2000;23:1545-50.

9. SÆvik O, Vestergaard H, Trygstad O, Pedersen O. Studies of insulin resistance in congenital generalized lipodystrophy. Acta Paediatr Suppl. 1996;413:29-38.

10. Bj/Ernstad PG, Foerster A, Ihlen H. Cardiac findings in generalized lipodystrophy. Acta Paediatr Suppl. 1996;413:39-43.

11. Bhayana S, Siu VM, Joubert GI, Clarson CL, Cao H, Hegele RA. Cardiomyopathy in congenital complete lipodystrophy. Clin Genet. 2002;61:283-7.

12. Viégas RFM, Diniz RVZ, Viégas MRF, Lira-Filho EB, Almeida DR. Cardiac involvement in total generalized lipodystrophy (Berardinelli-Seip Syndrome). Arq Bras Cardiol. 2000;75:246-8.

13. Petersen KF, Oral EA, Dufour S, Befroy D, Ariyan C, Yu C, et al. Leptin reverses insulin resistance and hepatic steatosis in patients with severe lipodystrophy. J Clin Invest. 2002;109: 1345-50.

14. Magré J. Identification of the gene altered in Berardineli-Seip congenital lipodystrophy on chromosome 11q13. Nat Genet. 2001;28: 365-70.

15. Maldergem LV, Magré J, Khallouf TE, Gedde-Dahl Jr T, Delépine M, Trygstad O, et al. Genotype-phenotype relationships in Berardinelli-Seip congenital lipodystrophy. J Med Genet. 2002;39:722-33.

Corresponding author:

Joel A. Lamounier

Faculdade de Medicina da UFMG - Departamento de Pediatria

Av. Alfredo Balena, 190

CEP 30130-100 - Belo Horizonte, MG, Brazil

Tel.: +55 (31) 3248.9632 - Fax: +55 (31) 3248.9664

E-mail: jalamo@medicina.ufmg.br 